Canadian Journal of Family and Youth, 7(1), 2015, pp 55-86

ISSN 1718-9748 () University of Alberta

http://ejournals.library.ualberta.ca/index/php/cjfy

\title{
The Foster Care Systems are Failing Foster Children: The Implications and Practical Solutions for Better Outcomes of Youth in Care
}

\author{
Mary Ramsay-Irving
}

\begin{abstract}
Although the foster care systems in North America are set up with good intentions for best practices for foster children, in reality these systems are failing youth in care. Many foster children experience more psychological, social, educational, behavioural, and emotional problems as compared to children who are not in foster care, and this can continue into adulthood. Attachment theory can help to explain why some children experience these problems. Professionals who work with this population need to have a good understanding of foster children's unique experiences in order to help them as much as possible. Literature has addressed the problems that foster children have faced for decades, but there seems to be little change that happens to address and prevent these problems. There is no doubt that there is a great need for change in the current foster care systems in North America because current outcomes for many foster children are negative. This paper reviews the literature on foster care and explains the issues that foster children experience. It also addresses why the foster care system is failing youth, and gives practical suggestions for solutions.
\end{abstract}

Mary Ramsay-Irving completed her Master of Counselling Degree from Athabasca University in April, 2013 and then became a Certified Canadian Counsellor (CCC) with the Canadian Counselling and Psychotherapy Association. She currently works as a mental health counselling therapist with individuals, youth, and couples at Hopeful Days Counselling in Oromocto, NB. She is also a Registered Counselling Therapist (RCT) with the New Brunswick Association of Counselling Therapists. She is very interested in the topics of the mental health of children, foster care, trauma, social justice, depression, and anxiety. 
Ramsay-Irving

\section{Introduction}

Foster care systems in North America differ in their policies and programs, but the overall issues that foster children experience in each jurisdiction remain very similar. The ultimate goal of foster care systems is that foster care is temporary and that eventually children go back home to their biological families whenever it is possible and safe to do so (Bruskas, 2008; Farmer, Southerland, Mustillo, \& Burns, 2009; Kolos, 2009; Mitchell, Kuczynski, Tubbs, \& Ross, 2010; Moro, Cassibba, \& Costantini, 2007; Reich, 2008). In some cases, foster children remain in care until adulthood and they age out of foster care (Schofield \& Beek, 2009). During their time in care, children can experience multifaceted difficulties in their lives and the foster care systems may worsen, or even cause, some of these problems (Price et al., 2008; Timmer, Sedlar, \& Urquiza, 2004). Professionals who work with this population need to have a good understanding of foster children's unique experiences in order to help them as much as possible. There is no doubt that there is a great need for change in the current foster care systems in North America because current outcomes for many foster children are negative.

For the purposes of this article, I will define foster care, also known as out-of-home care, as care away from the biological family which may be with relatives or non-relatives. It is to be a temporary substitute for the biological family (Clark et al., 2008; Craven \& Lee, 2006;

Eggertsen, 2008; Farmer, et al., 2009). There are different types of placements and the two most common placements for youth are foster homes and group homes (Clark et al., 2008; Farmer, et al., 2009; Nowacki \& Schoelmerich, 2010; Robst, Armstrong, \& Dollard, 2011). Bruskas (2008) stated that in 2008 there were 542,000 children in care in the United States. Although there are no specific statistics on how many foster children are in Canada, Ponti (2008) suggested that there were 76,000 children and youth in care in 2008 , and the numbers keep increasing every 
Foster Care Systems Failing Foster Children

year. The literature estimates that there are now more children in care than at any other time in North America (Mulcahy \& Trocme, 2010; Ponti, 2008).

There are various reasons why children enter into care and each situation is unique. Children are taken into care as a last resort and the main reasons are because of abuse inflicted upon the child by the caregiver, neglect, the inability of the parent to provide basic needs and/or supervision to the child. These issues could be due to parental drug abuse, extreme poverty, lack of coping and/or parenting skills, or other adverse situations (Chambers, Saunders, New, Williams, \& Stachurska, 2010; Simmel, 2007).

Even before entering foster care, many youth experience negative events and maltreatment in their lives which can have a negative impact on their development and functioning. Nearly half of foster children present with clinically significant issues while in care and in some instances the foster care system can exacerbate these problems (Bruskas, 2008; Chambers et al., 2010; Lewis, Dozier, Ackerman, \& Sepulveda-Kozakowski, 2007; Linares, Montalto, Li, \& Oza, 2006; Nowacki \& Schoelmerich, 2010; Tarren-Sweeney, 2010). Although the foster care systems in North America are designed with good intentions for best practices for foster children, in reality these systems are failing youth in care. Many foster children experience more psychological, social, educational, behavioural, and emotional problems as compared to children who are not in foster care, and this can continue into adulthood. Practical solutions must be further explored in order to ensure better outcomes for youth in foster care.

This paper will show the numerous issues that foster children experience and will give suggestions for practical solutions to help decrease these problems. I will write about the issues that foster children experience and explain the protective factors and interventions which may prevent or lessen these issues. In addition, I will address why the foster care systems are not 
Ramsay-Irving

working, and then I will present the changes and interventions which can be incorporated into the current system in order to improve outcomes for foster children. I will incorporate attachment theory into the main points in the article to help explain why some foster children experience negative outcomes and to inform the solutions that I present. Finally, I will give suggestions for future research on this topic.

\section{Attachment Theory and Foster Care}

Attachment theory can help to explain some issues that arise in foster care children. Attachment theory explains that a child needs a stable and ongoing relationship with a caregiver for his or her healthy development, especially in early childhood (Mitchell et al., 2010; Nowacki \& Schoelmerich, 2010; Schofield \& Beek, 2009). This means providing a secure base for children by providing ongoing protection, reliable support, and trust to allow the youth to explore their worlds (Broderick \& Blewitt, 2010; Schofield \& Beek). Attachment styles provide children with a working model of themselves, others, and their relationships which allows them to develop expectations about future relationships (Broderick \& Blewitt). The removal of the child from the birth family can be traumatic for children and they are vulnerable when entering foster care due to their past experiences (Broady, Stoyles, McMullan, Caputi, \& Crittenden, 2010; Bruskas, 2009). Transitioning to care is a stressful time and foster children experience loss of their primary attachment figure when they enter into care which can impact them in negative ways (Broderick \& Blewitt, 2010; Lewis et al, 2007). It is crucial to provide foster children with a consistent, caring, and stable environment which conducive to secure attachment. 
Foster Care Systems Failing Foster Children

\section{Secure and Insecure Attachments}

Securely attached children show positive attitudes towards themselves and others and are confident to explore their surroundings. They expect to be respected when they enter into relationships and they will also respect others (Broderick \& Blewitt, 2010). They also tend to have more friends and are more popular than insecurely attached children. Due to chronic maltreatment experienced by children before entering into care, the child may develop an insecure attachment style.

Insecurely attached children are more likely to act helpless, to act out behaviourally for attention, and may try to avoid seeking help even if they need it. They may be very demanding, overly controlling, overly dependent on caregivers, withdrawn or aggressive. In addition, they may avoid emotional expression and relationships with others (Schofield \& Beek, 2009). Insecure attachments correlate with psychopathology, developmental and mental health problems. This may partially explain some of the issues experienced by foster children (Nowacki \& Schoelmerich, 2010). I think it is important to note that attachment development serves an adaptive function to a child's environment. Children adapt to their environment and caregivers in a way that can help them to survive.

\section{Attachment and Stability Across Time}

Nowacki and Schoelmerich (2010) suggested that there still seems to be attachment plasticity in middle childhood. There has been some debate in the literature as to whether attachment can change or remain consistent throughout life. Craven and Lee (2006) applied attachment theory to the understanding of foster children and attachment styles. In their research synthesis, they argued that attachment style remained stable throughout a person's lifetime and that it affected the relationships of that person. They wrote that experiences could become 
Ramsay-Irving

encoded into people's memories creating schemas of attachment which are difficult to change. This was a helpful article to understand the experiences of foster children and the interventions that seemed to have positive outcomes. However, the articles studied in their paper did not have large sample sizes or random sampling. In addition, generalization to wider populations is not possible. Their view of attachment stability coincided with Broderick and Blewitt (2010) when they stated that early attachments could predict behaviours in later years and that the longer the attachment style was present in a person, the more difficult it was to change.

However, Broderick and Blewitt (2010) also reported that while attachment could predict later behaviours, it was also malleable and could change if caregiver quality changed in a significant way. Schofield and Beek (2009) reported on a part of a longitudinal study of 52 foster children called Growing Up In Foster Care, which took place between 1997-2006 and studied how developing a secure base and strong relationships between foster caregivers and foster children impacted children's well-being. Simmel's (2007) research showed results similar to Schofield and Beek's study. She conducted a longitudinal study of the risk and protective factors of 239 adopted foster children over an 8-year period. She found that attachment is malleable and can evolve. She also posited that a stable relationship with caregivers can positively affect foster children's relational and psychosocial adjustment. Simmel's study looked at younger children than Craven and Lee's (2006) report, and this may influence the results. If attachment is more malleable at earlier ages, then that may explain Simmel's findings. However, Schofield and Beek explored the secure base model with an adolescent age group and claimed that a positive relationship with caregivers can enhance resilience of adolescents and help them to become more secure in their relationships and experiences. Although the research is contradictory in some areas, the bottom line in all attachment research is that an ongoing, stable, supportive, trusting, 
Foster Care Systems Failing Foster Children

caring and attentive relationship with caregivers contributes to the healthy development of children.

\section{Foster Homes Versus Group Homes and Attachment}

As I stated earlier, the two main types of foster placements are foster homes and group homes. Research has shown that there are more positive outcomes for youth placed in foster families than in group homes. Researchers have found that the least restrictive settings that foster placements provide lead to the most positive outcomes for foster youth (Bakersman-Kranenburg et al., 2011; Farmer et al., 2009; Fulcher \& McGladdery, 2011; James et al., 2006; Kolos, 2009). This is most likely because of attachment. In institutions, the consistency and stability of relationships is limited with caregivers by shift work and job turnover which is a concern for the development of secure attachment in youth (Bakersman- Kranenburg et al., 2011; James et al., 2006; Kolos; Nowacki \& Schoelmerich, 2010; Tuner \& Macdonald, 2011). Stability and consistency are extremely important in the development of attachment for the healthy development of youth. Institutions, by their nature, cannot provide the much needed stability that youth require.

In a study of attachment styles of institutionalized children, $96 \%$ showed insecure attachment styles, and only 4\% were securely attached (Norwacki \& Schoelmerich, 2010). They generated these results by asking former foster youth to take the Adult Attachment Interview (AAI) and compared the results of former foster children and former institutionalized children. This may be a flawed method because the young adults may have experienced some different relationships after leaving care which may have altered their attachment styles, if attachment style is indeed malleable. They did not take into account the participants' experiences after leaving care when interpreting the results of the study. Taken at face value, these results are 


\section{Ramsay-Irving}

concerning when institutions are one of the most common types of placement. However, this does not imply that institutions can cause insecure attachment style in foster youth. Older children tend to be in institutions and they may have experienced maltreatment for longer periods of time before entering into care. These children may have developed an insecure attachment style because of maltreatment before entering an institution and they may not have experienced a secure, stable, and consistent relationship with a caregiver. Most importantly, this does not minimize the importance of establishing a secure base while in care, and institutions cannot do this optimally.

Robst, Armstrong and Dollard (2011) also conducted a study comparing the outcomes of youth in treatment foster care and treatment group care. They found that youth in treatment group care tended to have more serious emotional and behavioural issues than those in treatment foster care. Youth in the group setting were more likely to experience multiple placements, most likely due to difficult behaviours. In addition, the peer effects in the group setting may exacerbate the problems that foster youth experience. They found that youth in foster care settings had more positive outcomes and were less likely to experience multiple placements or commit serious crimes in the future. Robst et al. indicated that children in group homes most likely have more severe issues resulting in placement into those settings, whereas children in foster care settings usually have less severe issues when entering into care. This study had limitations, as they did not control for the previous behaviours or backgrounds of the youth. Therefore the comparisons did not indicate accurate outcomes of youth in treatment foster homes and treatment group homes. However, they did report helpful information about which youth backgrounds and behaviours may have influenced the placement setting of a foster child. 
Foster Care Systems Failing Foster Children

Bakersman-Kranenburg et al. (2011) explored the relationship between attachment and institutional placements as compared with children who had not experienced out-of-home care, and they found that normal development of youth requires that they live in a secure, stable, consistent environment with a supportive family. They also said that youth need to have opportunities to explore and learn from their environments, and institutionalized settings do not provide this. Bakersman-Kranenburg et al. found that children who live in a home environment, such as a foster placement, had more secure attachments and that a significant majority of youth living in institutionalized care showed insecure attachments. The results coincide with Nowacki and Schoelmerich's (2011) and Robst et al's (2011) studies. They attributed the secure attachments of some institutionalized children to their resilience. Bakersman-Kranenburg et al. also said that attachment theorists are critical of the premise that institutions could provide the ingredients for healthy development and attachment, yet children still end up in institutionalized settings. The system is failing children when placing them into institutions because it does not promote the elements determined by attachment theorists to develop in the healthiest way possible.

\section{Issues that Youth in Care may Experience before and when First Entering into Care}

Many children and youth may experience maltreatment by their parents before entering into care. Maltreatment may affect their developmental and psychological growth, as well as create attachment disorders (Bruskas, 2008; Nowacki \& Schoelmerich, 2010). Attachment disorders correlate with psychopathology and may explain some of the difficulties that many foster children experience (Lewis et al., 2007; Nowacki \& Schoelmerich). There are numerous possible results of child maltreatment. Some of these include post-traumatic stress disorder, 


\section{Ramsay-Irving}

depression and anxiety, self-esteem issues, and behaviour issues. Problems with relationships, educational difficulties, and substance abuse can also be a result of abuse (Simmel, 2007).

Bruskas (2008) conducted a literature review of children transitioning into care. She noted that when children come into care, professionals need to address the trauma and emotions experienced by the child early in the child's transition. Trauma and negative emotions can lead to negative developmental, educational and mental outcomes. Bruskas suggested that early developmental and mental health assessments can help professionals working with foster children to identify problems early and that they can choose interventions that may be most effective for the child. She also suggested that foster children entering into care should have an orientation to the system so they will know what to expect, much like new employees receive when first entering into a new job. Bruskas also posited that an orientation for youth in care would help to legitimize the child's experiences and to answer questions that the youth might have. This can decrease the anxiety, confusion, sadness, and stress associated with the transition into care. Furthermore, research could focus on whether these suggestions of early assessment and intervention, and orientation for children about the system help to create more positive outcomes for foster children.

Mitchell et al. (2010) reported on a portion of a hermeneutic phenomenological study called the Transitioning into Care Project (TICP) on foster children's unique experiences with transitioning into care. They obtained advice that the participants would give to other foster children, social workers, and foster parents. The authors noted that few studies addressed the perspectives of foster children even though it is important to listen to and understand their experiences. This Canadian study consisted of 20 children ranging in ages of 8 to 15 and who had been in foster care for between 6 to 36 months. The researchers interviewed the participants 
Foster Care Systems Failing Foster Children

using a semi-structured interview in a neutral location away from the foster home or social worker's office.

Mitchell et al. (2010) coded the interviews and compiled the main themes that they reported in their article. They found that most children experienced the removal from their homes as sudden and confusing. The children reported that during the transition, it was helpful for social workers to inform them about what is happening and to give them time to prepare for the move. They said it was important to become familiar with their new surroundings and the people who would care for them. The researchers reported that foster children needed more support and communication while going through the transition, and they required compassion and understanding from those involved with them. The participants also suggested that having a mentor, such as a former foster child, would benefit them and so they could know they are not the only ones that go through this experience. Children reported that it was important for them to stay in the same placement with the same people for stability and continuity of relationships with carers. The children also said that support from others, including counsellors, was important for them.

Mitchell et al's (2010) study was informative and gave readers a unique look at the youth's perspectives of transitioning into care. Although the study was comprehensive, one limitation was that the children who participated were from only one social services agency in Ontario. Therefore, the scope of the study was limited, as different jurisdictions have different policies and programs in place. I think it would be beneficial for future studies to include foster children's experiences from other geographical areas in order to gain a broader understanding of their experiences while transitioning into care. The information that foster children provide could help to inform practices which would lead to more positive experiences and outcomes for them. 
Ramsay-Irving

Foster children's experiences of transitioning into care are important for counsellors, social workers, and foster parents to understand so that they can help foster youth to better adjust to their situations. Without understanding and support, children transitioning into care may feel unheard, unsupported, scared, depressed, traumatized, and confused. If these feelings are not addressed early and effectively, this can impact their development and functioning.

\section{Multiple Placements}

Many foster children experience multiple placement disruptions, or placement "breakdowns". Eggertsen (2008) wrote that multiple placements are the most serious problem that children in care experience. Robst, Armstrong and Dollard (2011) echoed this idea when they reported that multiple placements are associated with negative outcomes such as depression, poor educational outcomes, and more behavioural problems. Research has shown that that multiple placements can increase internalizing and externalizing problems, difficulty forming attachments, problems in regulating emotions, and the development of a poor self-concept in foster youth (Price et al., 2008; Rostill Brookes et al., 2011; Smith, Stormshak, Chamberlain, \& Bridges Whaley, 2001). Those with unstable placements were twice as likely to have behaviour problems as compared to those who experienced stability early in their foster placements (Price et al., 2008). This could indicate that attachment style is the underlying issue.

Placement breakdowns involve youth having to move into another foster care setting because of a variety of circumstances. Rostill-Brooks et al. (2011) defined placement disruption as a "premature termination of a foster placement" (p. 104). Although each situation is unique, there are common elements associated with placement breakdowns of foster placements. The effects of multiple placements on foster children can develop into a cycle. Kolos (2009) cited 
Foster Care Systems Failing Foster Children

concerning statistics and said that foster children experience, on average, nine foster placements before entering residential care.

The instability caused by multiple placements and placement breakdowns can affect foster children emotionally, psychologically, behaviourally, socially, and educationally. The history of multiple placements also leads to higher mental health services usage (Chambers, Saunders, New, Williams, \& Stachurska, 2010; Craven \& Lee, 2006; Eggertsen, 2008; Farmer et al., 2009; Kolos, 2009; Lewis et al., 2007; Price et al., 2008; Rostill-Brookes et al., 2011; Scherr, 2007; Simmel, 2007; Smith, Stormshak, Chamberlain, \& Bridges-Whaley, 2001; TarrenSweeney, 2010; Turner \& Macdonald, 2011).

Eggertsen (2008) and Rostill-Brookes et al. (2011) both conducted studies to understand what leads to placement breakdowns and the effects of multiple placements. Rostill-Brookes et.al's study was a qualitative Interpretative Phenomenological Analysis (IPA) inviting youth in care, their foster parents and social workers to describe their experiences of placement breakdowns. Studies conducted from the youth's perspectives are rare, but it is important to give foster children a voice to respect their rights and their dignity, and to help us understand their experiences in care (Bruskas, 2009; Mitchell et al., 2010; Rostill-Brookes et al., 2011). Mitchell et al. (2010) also conducted a study which incorporated foster children's views and allowed them to give advice to other youth in care and to foster parents and social workers.

I conclude that stability throughout a child's life is important and when they have numerous people coming in and out of their lives, it has a negative impact on attachment, placement stability, and overall functioning. Multiple placements have numerous effects on foster children's well-being, in addition to attachment problems, and I will explain some of these effects below. 
Ramsay-Irving

\section{Attachment and Multiple Placements}

Children who have insecure attachment styles may have their working models of relationships reinforced when they experience multiple placements. In turn, several placements may also promote or sustain psychological, behavioural, emotional and educational problems (Rostill-Brookes et al., 2011). This can be detrimental to development of attachment when they do not have a stable attachment figure. Poor attachment styles may result in multifaceted issues, and multiple placements and institutionalization can exacerbate these issues. Craven \& Lee (2006) wrote that foster care disrupts attachments and that the making and breaking of attachments affects the child's attachment style and their emotional well-being. This could interfere with forming future healthy relationships. Insecure attachment styles may be a major underlying cause of the problems foster children experience.

A foster caregiver's own expectations about how the child is going to respond to the parent, as well as how the child perceives his or her new environment can also be factors in developing attachments and bonds (Broady et al., 2010; Mitchell et al., 2010, Nowacki \& Schoelmerich, 2010; Schofield \& Beek, 2009). Mental health professionals can work with carers on parenting strategies and on building safety and security within the home for the child. They can also teach foster parents ways to develop stronger bonds with foster youth.

\section{Psychological Issues}

Most authors in the literature agree that there are a high percentage of foster children who display mental health issues as compared to children who are not in care. Many researchers have suggested that almost half of foster children display clinically significant mental health problems (Craven \& Lee, 2006; Eggertsen, 2008: Lewis et al., 2007; Price et al., 2008; Tarren-Sweeney, 2010; Timmer et al., 2004). Craven \& Lee (2006), Price et al. (2008), and Timmer et al. (2004) 
Foster Care Systems Failing Foster Children

also found that multiple placements contribute to the worsening of mental health issues in some foster children. Craven \& Lee reported that there was a relationship between extended stays in foster care and short and long term bio-psychosocial problems in foster children. I speculate from the research that children who are in care for longer periods of time may experience more placements and little consistency and this may contribute to their bio-psychosocial issues. Again, attachment theory may be able to explain these findings. Abuse may have first contributed to some of the attachment and mental health issues experienced by foster children. Without having a secure base with consistency, stability and a sense of security while in care, it may contribute to insecure attachment which is correlated with psychopathology (Nowacki \& Schoelmerich, 2010).

\section{Emotional Issues}

Multiple separations from caregivers, parents, and friends can have a permanent emotional impact in foster children. When children leave everything familiar behind it can cause stress, anxiety, a feeling of vulnerability and loss of control (Bruskas, 2008; Craven \& Lee, 2006; Kolos, 2009; Rostill-Brookes et al., 2011). Foster children who experience placement disruptions also have problems with emotional regulation (Rostill-Brookes et al., 2011).

In their qualitative study, Rostill-Brookes et al. (2011) identified issues regarding emotional effects of multiple placements. They found that some youth may hide their emotions during placement breakdowns. Bruskas (2008) also wrote on this subject and thought it was a form of oppression that foster children were not being able to express their opinions or emotions. Bruskas went on to say that the foster care systems create a "systemic constraint" (p. 72) when it prevents foster youth from feeling a sense of competence or when they feel that they cannot tell adults their concerns. I think that oppression of foster children continues because of the lack of 
Ramsay-Irving

change in the foster care system. Carers of the youth may underestimate the impact that various types of foster placements and multiple placements have on youth when the youth feel they cannot express their emotions. I can conclude from these findings that the youth do not feel heard by adults and they try to hide their emotions. The result is an underestimation of the impact of multiple placements on youth, as well as oppression and disempowerment by the system.

\section{Behavioural Issues}

Price et al. (2008) compared placement stability and child behaviours and they found that multiple placements contributed to an increase in externalizing and internalizing behaviours, even after controlling for levels of prior behavior problems. Lewis et al. (2007) found that foster children were less likely to develop self-regulatory skills. They also found that there was a greater risk of lowered inhibitory control when children experience multiple placements. This was associated with hyperactivity, conduct problems, aggression, and social incompetence. They reported, along with Clark et al. (2008), that there was a higher rate of incarceration and more severe symptoms of conduct disorder among adolescents who experienced more than one placement. Chambers et al. (2010) found that there are high rates of aggressive and oppositional behaviours in foster children, and that $48 \%$ of foster children had clinically significant behaviour disorders.

Clark et al. (2008) studied runaway behaviour of children in foster care. The lower inhibitory control abilities of some foster children could contribute to runaway behaviours and other high risk behaviours (Lewis et al., 2007). Running away may also inhibit the youth's abilities to develop important life skills or important social supports that they require. Foster children's behaviours can worsen as they continue to experience inconsistent and unstable placements and relationships. 
Foster Care Systems Failing Foster Children

\section{Social Issues}

There are numerous social effects associated with being in care. Many foster children have trouble developing positive relationships with their peers. Behaviour problems, insecure attachment styles, and the lack of social skills may contribute to problems with making positive friendships. Stigmatization can also affect foster youth socially, and foster children's peers might tease and scrutinize them (Bruskas, 2008; Craven \& Lee, 2006; Fulcher \& McGladdery, 2011). Diagnostic labelling can stigmatize foster children and can influence the way people treat them (Fulcher \& McGladdery, 2011). Foster children may feel like they do not fit in at school and this could lead to school phobias and truancy, leading to more problems (Craven \& Lee, 2006). In addition, foster children may start to feel like they are not normal and this could affect identity development (Schofield \& Beek, 2009). It is of utmost importance that children in care experience a positive, nurturing, supportive, secure and stable relationship with their caregivers in order to develop a healthy attachment style with their caregivers, with their peers, and with later intimate relationships.

\section{Educational Issues}

Foster children may experience educational difficulties associated with being in care (Bruskas, 2008; Chambers et al., 2010; Eggertsen, 2008; Scherr, 2007). Foster children display high rates of behavioural problems, inhibitory control problems, speech and language problems, and developmental delay. These can have a negative impact on school experiences (Chamber et al., 2010; Lewis et al., 2007). Scherr (2007) conducted a study of the educational achievements of foster children and she reported that children in care were overrepresented in special education programs. This could be a result of children in care participating in more assessments and then is determined that they are in need of special education. It could also be the result of missed time at 
Ramsay-Irving

school because of numerous school changes that many foster children experience (Bruskas, 2008; Scherr, 2007). Scherr (2007) questioned whether special education was the correct intervention for foster children. Bruskas also said that the challenges of moving to new schools could be stressful for foster children, resulting in discomfort that could impact school performance.

Behaviour problems of foster children at school are another issue that can affect school outcomes. Scherr (2007) found that during their time in school, $24 \%$ of foster youth were expelled or suspended. They were 3 times more likely to be disciplined for behavior than for children who are not in care.

There were limitations to Scherr's study in that she did not include foster children living in group homes and treatment centers. However, these settings are two of the main types of placements where foster children live, and therefore we cannot generalize the results to the entire population of foster children. Children in institutionalized settings tend to exhibit more problems than those in foster homes, and it is likely that they would have poorer educational outcomes than the sample included in Scherr's study.

Bruskas (2008) noted a major concern resulting from school problems in foster children. She said that about $90 \%$ of foster children attend high school, but less than half of those will graduate. On a more positive note, Bruskas also reported that $89 \%$ of foster children completed a general educational development (GED) rather than finishing high school, showing that they still obtain some education. Bruskas also said that only $1.8 \%$ of foster children attend post secondary education which is concerning considering that many current jobs require education beyond high school. 
Foster Care Systems Failing Foster Children

\section{Issues when Aging out of Care}

Many of the concerns I addressed above can affect the outcomes of foster youth who age out of care. Usually foster youth "age out" at the age of 18. Many foster youth find the transition from foster care to adulthood difficult and find themselves on their own with few financial or social supports (Bruskas, 2008). Simmel's (2007) longitudinal study of the psychosocial wellbeing of foster children found that behaviour problems of foster children were stable and sustained throughout the children's lives into adulthood. Bruskas reported that many foster youth who age out of care tend to have mental health issues, addictions, criminality, and the inability to function productively in society, resulting in problems maintaining a job. The lack of education can contribute to problems with finding a good-paying job, resulting in more financial hardships which may further fuel criminality. A high percentage of foster youth who age out of care are homeless when compared to the general population (Bruskas). The lack of social supports, most likely caused by the inconsistent and unstable relationships throughout their lives, may result in former foster children feeling lonely, devastated, and experiencing great levels of stress. The outcomes are negative for some former foster youth and the system needs to find new ways to produce better outcomes.

\section{Protective Factors}

The main theme in the literature regarding protective factors is providing a supportive, caring, predictable, stable, and safe environment with consistency in relationships (Broderick \& Blewitt, 2010; Bruskas, 2008; Clark et al., 2008; Lewis et al., 2007; Nowacki \& Schoelmerich, 2010; Rostill-Brookes et al., 2011; Schofield \& Beek, 2009; Simmel, 2007). This can enhance resilience in foster children and help in the development of self-regulation. I cannot stress enough just how important it is for the development of a secure base involving a stable, secure, 
Ramsay-Irving

and caring relationship with foster children. Giving foster youth a voice and including them in decision making can help them to develop a sense of control, self-esteem and self-efficacy in their lives (Broady et al., 2010; Bruskas; Craven \& Lee, 2006; Fulcher \& McGladdery, 2011; Mitchell et al., 2010; Rostill-Brookes et al., 2011).

\section{Why the Foster Care System is Failing Youth}

The foster care systems are not working, which is evident from the issues that foster children currently experience and the negative outcomes of foster youth compared to youth who are not in care. I explained the problems that foster children experience in this paper and the problems that stem from system failures. I think that multiple placements are probably the greatest failure of the system. Multiple placements inhibit children from being able to experience stability and consistency or to provide a secure base for the child, leaving children vulnerable and powerless (Bruskas, 2008; Rostill-Brookes et al., 2011). Current interventions tend to ignore the attachment problems of youth who lose their primary attachment figures when they first enter into care (Craven \& Lee, 2006). Also, the main focus of foster care is to return the foster children to their biological families after their temporary placement in care, but there needs to be a balance with trying to decide what is best for each child.

Child welfare workers decide the case plans for the youth in care and the youth do not always have input into their own lives. This renders the children powerless, and the systems do the youth a disservice without their input (Bruskas, 2008; Rostll-Brookes et al., 2010). Social workers decide on the types of placements for the children but decisions are often based upon resource-led rather than a needs-led basis (Rostill-Brookes et al., 2011). Resources are limited and foster homes are scarce, and these problems are getting worse. 
Foster Care Systems Failing Foster Children

Institutionalized care can lead to more negative outcomes than foster children in foster families. However, institutions are still widely used in the systems, even though the evidence shows negative outcomes. Foster homes seem to have the most positive outcomes for foster children, but there is a shortage of foster families available for foster placements. Furthermore, foster parents do not always get the necessary training they need or the support they require.

Another problem with the system is that research has long informed child welfare systems about successful interventions but it is difficult for frontline staff to put this research into practice (Parker et al., 2009). Purely research-based programs do not always work because frontline staff may not always understand it, or feel it is not practical to use in a work setting. At other times, workers are not interested in trying it in their everyday jobs as it may increase their workloads. There are miscommunications and gaps in the foster care systems. Foster care affects all involved in different ways, and policies need to help address the problems that all stakeholders perceive (Moro et el., 2007). Frontline workers, foster parents, social workers, foster youth and biological families are experts on their own experiences but in many instances their voices are not being heard (Moro et al., 2007).

Children in care are often disempowered, vulnerable, and oppressed (Bruskas, 2008). The system perpetuates this cycle of oppression and the cycle needs to be broken. Also, many foster children do not learn adequate coping and life skills while in care and many do not have the supports or planning needed for when they age out of care. These deficiencies are setting them up for failure when they do become adults and are out on their own.

\section{Practical Changes and Interventions that can Improve Outcomes}

I have described in detail the problems of the foster care system and how they are failing youth in care. The information presented seems bleak, but the current foster care system can 
Ramsay-Irving

incorporate practical solutions to try to help foster children have more positive outcomes.

Changing the system cannot happen overnight, but small steps can help make a difference in reaching the ultimate goal of helping foster children have better outcomes.

\section{Drawing Upon Protective Factors}

The system can draw upon the protective factors of youth in care. The main protective factor is providing children with a supportive, caring, consistent, and stable relationship with a caregiver. Giving children the opportunity to experience such a relationship can help with attachment issues and can help improve outcomes for youth. Foster parents who make time everyday to talk with the youth and do activities together can make foster children feel like they belong in the family. This can help to create much needed stability and trust in the child's life (Clark et al., 2008; Fulcher \& McGladdery, 2011). Youth in group homes would also benefit from a supportive, caring, predictable, and stable relationship with a caregiver. This caregiver could be a carer from outside of the group home who comes in regularly to spend time with the youth.

\section{Foster Parent Assessment, Training, and Support}

As another intervention, I suggest assessment of foster parents for parental readiness for the unique needs and behaviours of foster children. Foster parent training needs to address the foster parent's expectations of fostering youth, and all background information about the child must be given to the foster parents (Kolos, 2009; Moro et al., 2007; Rostill-Brookes et al., 2011; Simmel, 2007). The second step is improved and more in-depth foster parent training and more supports for them (Chambers et al., 2010; DeGarmo et al., 2009; Kolos, 2009; Turner \& Macdonald, 2011). I suggest these steps because multiple placements occur due to the child's 
Foster Care Systems Failing Foster Children

behavioural and relational problems. If foster parents are ready, hold realistic expectations, and have the knowledge and skills to deal with and cope with foster children's behaviours, there is a lower chance of placement breakdowns, resulting in more stable placements. Sadly, there are not enough foster parents in the system, and there is a need to recruit, appropriately train, and retain foster parents. I suggest giving adults more incentives to become foster parents. Foster parents need significantly more compensation, respect and recognition, ongoing and sufficient support from supervisors, and ongoing training to attract and keep foster parents in the system. I think that they are a very important asset for the foster care system and people in the system need to treat them as such.

\section{Assessing Youth's Needs When Entering into Care}

Assessing children who come into care is also an important intervention to match them with appropriate services and types of placements (Farmer et al., 2009; James et al., 2006). Assessing foster children's needs also helps professionals to choose the best therapeutic interventions and community resources for the youth (Craven \& Lee, 2006). Interventions require a multidisciplinary approach (Craven \& Lee, 2006; Fulcher \& McGladdery, 2011; Kolos, 2009). This can include the foster parents, mental health professionals, school personnel, the foster child's biological family when possible, social workers, and the foster youth. However, this may be difficult with a lack of resources, and more resources should be allocated for this purpose.

\section{Putting Research into Practice}

The onus to help foster children does not solely lie with foster parents, social workers and supervisors, but also with experts who research the issues and inform policy. The ability to put 


\section{Ramsay-Irving}

research into practice is the key to change (Murray et al., 2010; Parker et al., 2009). Parker et al. (2009) wrote about a quality-improvement dialogue between frontline staff, managers, and experts to improve foster care. They noted that communication of all involved is the key to putting research into practice to improve foster care for the youth. They posited that experts are in the best position to design programs, but that they also need input from managers and frontline staff to determine how it works in the real world. Parker et al. concluded that the best way to ensure implementation and sustainability of quality programs is for experts to provide guidelines for frontline staff to follow, but that frontline staff can customize the programs to fit within their facilities. An ongoing dialogue and support between frontline workers, managers, and experts is important in order to create and implement changes into agencies, which requires regular meetings and contact between all involved. Parker et al. suggested that organizations need to make time for quality improvement implementation. This may require a significant amount of time and resources early in the change process, but agencies can benefit from improved quality of care in the long run. They conducted their study in health care settings, but I think that foster care systems can also successfully implement a quality-improvement dialogue between all levels and to have frontline workers help inform policy and practice.

\section{Incorporating Youth's Perspectives}

It is also important to listen to foster children's experiences and to take into account what they think needs to change. It would be beneficial to include youth in quality improvement dialogues, and also in their case plans and other decisions whenever possible (Bruskas, 2008; Clark et al., 2006; Eggertsen, 2008; Fulcher \& McGladdery, 2011; Mitchell, Kuczynski, Tubbs, \& Ross, 2010; Rostill-Brookes et al., 2011). This gives youth the sense that they are empowered, and that they have some control over their lives (Bruskas, 2008). Also keeping youth informed 
Foster Care Systems Failing Foster Children

about what is going on is important because when children do not know what is going on with their lives, it can cause feelings of vulnerability and powerlessness (Bruskas; Rostill-Brookes et al.).

\section{Implementing Strength-Based Approaches}

To increase self-efficacy and self-esteem in youth, it would be helpful for those involved in the care of the youth to implement strength-based approaches into their everyday lives. Using a strength-based approach may be an effective way to build resilience and self-confidence in foster children (Chambers et al., 2010; Farmer et al., 2009; Fulcher \& McGladdery, 2011). Using this type of approach may also help foster youth who age out of care to realize that they can draw upon their strengths in order to make their lives better when they are on their own. There seems to be a social stigma attached to being a foster child and many seem to hold lower expectations for children in care (Fulcher \& McGladdery; Schofield \& Beek, 2009). Using a strength-based approach can increase resilience of foster children, which may lessen the impact of stigmatization. School personnel can also be educated on the unique situations of foster youth. Teachers and foster parents can work together to teach foster children to make positive choices, and to learn new skills (Craven \& Lee, 2006). This can provide consistency between the school and home environments and may help to create better outcomes for youth in all areas of their lives.

\section{More Supports and Planning as Youth Age Out of Care}

Finally, foster youth who age out of care need more supports and a plan in place before they transition into adulthood. It is important for foster parents or other caregivers to continue to provide a secure base to foster youth who transition out of care (Schofield \& Beek, 2009). 


\section{Ramsay-Irving}

Maintaining ongoing support throughout the foster child's life may help enhance resilience of the youth as they enter into adulthood (Nowacki \& Schoelmerich, 2010).

Transitions are difficult times for youth, and it can be especially stressful for foster youth who are aging out of care. Foster carers need to help prepare the youth to be ready for independence while providing the support they need (Schofield \& Beek, 2009). It is also important for youth to be knowledgeable about community resources that they can access to help them when needed. Planning the transition into adulthood should start early in care and continue until the child ages out.

\section{Conclusion}

I have described the issues that foster care children face while in care and the ways in which the system perpetuates these issues. Attachment theory can help to explain many of the problems foster children experience and it can help inform interventions which may be successful in providing positive outcomes for foster youth. I have shown that providing children with a secure base consisting of a stable, ongoing, caring, responsive, and consistent relationship with a caregiver is the most important intervention for better youth outcomes.

I have also shown that although the foster care systems in North America are designed with good intentions for best practices for foster children, in reality these systems are failing youth in care. Many foster children experience more psychological, social, educational, behavioural, and emotional problems as compared to children who are not in foster care, and this can continue into adulthood. Multiple placements, lack of early assessments, institutionalized care, and the loss of a primary attachment figure leads to these problems. Oppression, systemic constraint of foster youth by the foster system, and the lack of preparation when aging out of the system also contribute to negative outcomes. 
Foster Care Systems Failing Foster Children

Professionals who work with this population need to have a good understanding of foster children's unique experiences in order to help them as much as possible. The system also needs to change by implementing new policies and procedures with the input of all involved. Although this takes time, extra work, and resources, it would increase long-term positive outcomes of youth. In the long run, systemic changes can be more cost-effective and create greater rates of positive outcomes of youth in care.

I suggest that future research should focus on which early assessment and interventions are most effective for children in care. Another suggestion is to conduct more research on which effective interventions are best to help attachment issues in foster children. Future research needs to incorporate foster children's perspectives and experiences of foster care so that researchers and professionals can continue to understand the impact on them. New school interventions need to be explored as educational outcomes of many foster youth are poor. Finally, there also needs to be a better understanding of which specific supports foster youth need as they transition out of care into adulthood.

Taking small steps in order to change policy and practice can help the foster care system. We can start by implementing changes into the existing system. Future research can inform larger changes. My hope is that in the future, parts of the ideology, policy, and practice that are not working in the foster care system can be broken down and then rebuilt so that we can ensure that foster children and youth experience the best outcomes possible. 
Ramsay-Irving

\section{References}

Bakersman-Kranenburg, M. J., Steele, H., Zeanah, C. H., Muhamedrahimov, R. J., Vorria, P., Dobrovo-Krol, N. A., Steele, M., van Ijzendoorn, M. H., Juffer, F., \& Gunnar, M. (2011). Attachment and emotional development in institutional care: Characteristics and catch up. Monographs of the Society for Research in Child Development, 76(4), 62-91. doi: $10.1111 / \mathrm{j} .1540-5834.2011 .00628 . \mathrm{x}$

Broady, T. R., Stoyles, G. J., McMullan, K., Caputi, P., \& Crittenden, N. (2010). The experiment of foster care. Journal of Child and Family Studies, 19, 559-571. doi: 10.1007/s10826009-9330-6

Broderick, P. C., \& Blewitt, P. (2010). The life span: Human development for helping professionals ( $3^{\text {rd }}$. Ed.). Upper Saddle River, N.J: Pearson Education.

Bruskas, D. (2008). Children in foster care: A vulnerable population at risk. Journal of Child and Adolescent Psychiatric Nursing, 21, 70-77. doi: 10.1111/j.1744-6171.2008.00134.x

Clark, H. B., Crosland, K. A., Geller, D., Cripe, M., Kenney, T., Neff, B., \& Dunlap, G. (2008). A functional approach to reducing runaway behaviour and stabilizing placements for adolescents in foster care. Research on Social Work Practice, 18, 429-441. doi: $10.1177 / 1049731508314265$

Chambers, M. F., Saunders, A. M., New, B. D., Williams, C. L., \& Stachurska, A. (2010). Assessment of children coming into care: Processes, pitfalls and partnerships. Clinical Child Psychology and Psychiatry, 15, 511-527. doi: 10.1177/1359104510375932

Craven, P. A., \& Lee, R. E. (2006). Therapeutic interventions for foster children: A systematic research synthesis. Research on Social Work Practice, 16, 287- 304. doi: $10.1177 / 1049731505284863$ 
Foster Care Systems Failing Foster Children

DeGarmo, D. S., Chamberlain, P., Leve, L. D., \& Price, J. (2009). Foster parent intervention Engagement moderating child behavior problems and placement disruption. Research on Social Work Practice, 19, 423- 433. doi: 10.1177/1049731508329407

Eggertson, L. (2008). Primary factors related to multiple placements for children in out-of-home care. Child Welfare, 87(6), 71-89. Retrieved from http://0- go.galegroup.com.aupac.lib. athabascau.ca/ps/i.do?\&id=GALE\% 7CA218882477\&v=2.1\&u=atha49011\&it=r\&p=PPP $\mathrm{C} \& \mathrm{sw}=\mathrm{w}$

Farmer, E. M. Z., Southerland, D., Mustillo, S. A., \& Burns, B. J. (2009). Returning home in systems of care: Rates, predictors and stability. Journal of Emotional and Behavioral Disorders, 17, 133-146. doi: 10.1177/1063426608327002

Fulcher, L. C., \& McGladdery, S. (2011). Re-examining social work roles and tasks with foster care. Child \& Youth Services, 32, 19-38. doi: 10.1080/0145935X.2011.553579

James, S., Leslie, L. K., Hurlburt, M. S., Slymen, D. J., Landsverk, J., Davis, I., Mathiesen, S.G., \& Zhang, J. (2006). Children in out-of-home care: Entry into intensive or restrictive mental health and residential care placements. Journal of Emotional and Behavioral Disorders, 14, 196-208. doi: 10.1177/10634266060140040301

Kolos, A. C. (2009). The role of play therapists in children's transitions: From residential care to foster care. International Journal of Play Therapy, 18, 229-239. doi: 10.1037/a0016336

Lewis, E. E., Dozier, M., Ackerman, J., \& Sepulveda-Kozakowski, S. (2007). The effect of placement instability on adopted children's inhibitory control abilities and oppositional behavior. Developmental Psychology, 43, 1415-1427. doi: 10.1037/0012-1649.43.6.1415

Linares, L.O., Montalto, D., Li, M., \& Oza, V.S. (2006). A promising parenting intervention in foster care. Journal of Consulting and Clinical Psychology, 74, 32-41. doi:

10.1037/0022-006X.74.1.32 


\section{Ramsay-Irving}

Mitchell, M.B., Kuczynski, L., Tubbs, C.Y., \& Ross, C. (2010). We care about care: Advice by children in care for children in care, foster parents and child welfare workers about the transition into foster care. Child and Family Social Work, 15, 176-185. doi:

10.1111/j.1365-2206.2009.00657.x

Moro, G., Cassibba, R., \& Costantini, A. (2007). Focus groups as an instrument to define Evaluation criteria: The case of foster care. Evaluation, 13, 340-357. doi: $10.1177 / 1356389007078626$

Mulcahy, M., \& Trocme, N. (2010). Children and youth in out-of-home care in Canada. CECW Information Sheet, 78E, 1-2. Retrieved from http://www.cecw-cepb.ca/publications/1720

Murray, M.M., Southerland, D., Farmer, E.M., \& Ballentine, K. (2010). Enhancing and adapting treatment foster care: Lessons learned in trying to change practice. Journal of Child and Family Studies, 19, 393-403. doi: 10.1007/s10826-009-9310-х

Nowaki, K., \& Schoelmerich, A. (2010). Growing up in foster families or institutions: Attachment representation and psychological adjustment of young adults. Attachment and Human Development, 12, 551-566. doi: 10.1080/14616734.2010.504547

Parker, L.E., Kirchner, J.E., Bonner, L.M., Fickel, J.J., Ritchie, M.J., Simons, C.E., \& Yano, E.M. (2009). Creating a quality-improvement dialogue: Utilizing knowledge from frontline staff, managers, and experts to foster health care quality improvement. Qualitative Health Research, 19, 229-242. doi: 10.1177/1049732308329481

Ponti, M. (2008). Special considerations for the health supervision of children and youth in foster care. Paediatriatric Children's Health, 13, 129-132. Retrieved from http://www.cps.ca/english/statements/CP/cp08-01.htm 
Foster Care Systems Failing Foster Children

Price, J.M., Chamberlain, P. , Landsverk, J., Reid, J.B., Leve, L.D., \& Laurent, H. (2008). Effects of a foster parent training intervention on placement changes of children in foster care. Child Maltreatment, 13, 64-75. doi: 10.1177/10775595507310612

Reich, J.A. (2008). The child welfare system and state intervention in families: From historical patterns to future questions. Sociology Compass, 2(3), 888-909. doi: 10.1111/j.17519020.2008.00111.x

Robst, J., Armstrong, M., \& Dollard, N. (2011). Comparing outcomes for youth served in treatment foster care and treatment group care. Journal of Child and Family Studies, 20, 696-705. doi: 10.1007/s10826-011-9447-2

Rostill-Brooks, H., Larkin, M., Toms, A., \& Churchman, C. (2011). A shared experience of fragmentation: Making sense of foster placement breakdown. Clinical Child Psychology and Psychiatry, 16, 103-127. doi: 10.1177/1359104509352894

Scherr, T.G. (2007). Educational experiences of children in foster care: Meta-Analysis of special education, retention and discipline rates. School Psychology International, 28, 419- 436. doi: 10.1177/0143034307084133

Schofield, G., \& Beek, M. (2009). Growing up in foster care: Providing a secure base through adolescence. Child and Family Social Work, 14, 255-266. doi: 10.1111/j.13652206.2008. 00592.x

Simmel, C. (2007). Risk and protective factors contributing to the longitudinal psychosocial well-being of adopted foster children. Journal of Emotional and Behavioral Disorders, 15, 237- 249. doi: 10.1177/10634266070150040501 


\section{Ramsay-Irving}

Smith, D.K., Stormshak, E., Chamberlain, P., \& Bridges-Whaley, R. (2001). Placement disruption in treatment foster care. Journal of Emotional and Behavioral Disorders, 9, 200-205.

Tarren-Sweeney, M. (2010). Concordance of mental health impairment and service utilization among children in care. Clinical Child Psychology and Psychiatry, 15, 481-495. doi: 10:1177/1359104510376130

Timmer, S.G., Sedler, G., \& Urquiza, A.J. (2004). Challenging children in kin versus nonkin foster care: Perceived costs and benefits to caregivers. Child Maltreatment, 9, 251-262. doi: $10.1177 / 1077559504266998$

Turner, W., \& Macdonald, G. (2011). Treatment foster care for improving outcomes in children and young people: A systematic review. Research on Social Work Practice, 21, 501-527. doi: $10.1177 / 1049731511400434$ 